\section{Kidney \\ Blood Pressure Research}

\title{
PKB/SGK-Resistant GSK-3 Signaling Following Unilateral Ureteral Obstruction
}

\author{
Jakob Voelkla Sobuj Miaa Adrian Meissnera ${ }^{a} \quad$ Mohamed S. Ahmed ${ }^{a}$ \\ Martina Feger ${ }^{a}$ Bernat Elvira ${ }^{a}$ Britta Walker ${ }^{a}$ Dario R. Alessi ${ }^{b}$ Ioana Alesutan ${ }^{a}$ \\ Florian Lang ${ }^{\text {a }}$
}

${ }^{a}$ Department of Physiology, University of Tübingen, Tübingen, Germany; ${ }^{b}$ MRC Protein Phosphorylation Unit, Department of Biochemistry, University of Dundee, UK

\section{Key Words}

Protein kinase B • Serum- and glucocorticoid-inducible kinase $•$ Glycogen synthase kinase 3 • Unilateral ureteral obstruction $\bullet$ B-catenin $\bullet$ Wnt $\bullet$ Renal fibrosis

\begin{abstract}
Background/Aims: Renal tissue fibrosis contributes to the development of end-stage renal disease. Causes for renal tissue fibrosis include obstructive nephropathy. The development of renal fibrosis following unilateral ureteral obstruction (UUO) is blunted in gene-targeted mice lacking functional serum- and glucocorticoid-inducible kinase SGK1. Similar to Akt isoforms, SGK1 phosphorylates and thus inactivates glycogen synthase kinase GSK-3. The present study explored whether PKB/SGK-dependent phoshorylation of GSK-3 $\alpha / \beta$ impacts on pro-fibrotic signaling following UUO. Methods: UUO was induced in mice carrying a PKB/SGK-resistant GSK$3 \alpha / \beta\left(g s k-3^{K l}\right)$ and corresponding wild-type mice $\left(g s k-3^{W}\right)$. Three days after the obstructive injury, expression of fibrosis markers in kidney tissues was analyzed by quantitative RT-PCR and western blotting. Results: GSK- $3 \alpha$ and GSK-3 $\beta$ phosphorylation was absent in both, the non-obstructed and the obstructed kidney tissues from $g s k-3^{K I}$ mice but was increased by UUO in kidney tissues from $g s k-3^{W T}$ mice. Expression of $\alpha$-smooth muscle actin, type I collagen and type III collagen in the non-obstructed kidney tissues was not significantly different between $g s k-3^{K I}$ mice and $g s k-3^{W T}$ mice but was significantly less increased in the obstructed kidney tissues from $g s k-3^{K l}$ mice than from $g s k-3^{W T}$ mice. After UUO treatment, renal B-catenin protein abundance and renal expression of the B-catenin sensitive genes: $c-M y c, D k k 1$, Twist and Lef1 were again significantly less increased in kidney tissues from $g s k-3^{K l}$ mice than from gsk$3^{W T}$ mice. Conclusions: PKB/SGK-dependent phosphorylation of glycogen synthase kinase GSK-3 contributes to the pro-fibrotic signaling leading to renal tissue fibrosis in obstructive nephropathy.
\end{abstract}




\section{Kidney \\ Blood Pressure Research}

Kidney Blood Press Res 2013;38:156-164

\begin{tabular}{l|l}
\hline DOI: $10.1159 / 000355763$ & (C) 2014 S. Karger AG, Basel
\end{tabular}

Published online: March 15, 2014

www.karger.com/kbr

Resistant GSK-3 in UUO

\section{Introduction}

Renal tissue fibrosis is a major pathophysiological mechanism leading to end-stage renal failure in the course of diabetes, hypertension, renal ischemia and obstructive nephropathy $[1,2]$. The renal pathology of chronic kidney disease is characterized by tubulo-interstitial fibrosis due to matrix deposition by myofibroblasts [3]. Myofibroblasts could originate from resident fibroblasts, bone-marrow-derived cells or from epithelial to mesynchymal transition (EMT), by which endothelial cells, glomerular podocytes and renal tubular cells transform into mesenchymal cells [3-5]. Myofibroblasts express mesenchymal cell products, such as $\alpha$-smooth muscle actin ( $\alpha$-Sma) and collagen [6].

Renal fibrosis is a hallmark of chronic kidney disease, regardless of its initial cause $[1,2,7]$. The process of renal fibrosis involves various signaling pathways, most notably the transforming growth factor TGFß pathway $[1,2,6]$. TGFß is involved in renal fibrosis following obstructive injury, diabetic nephropathy and other renal diseases [2]. TGFß strongly stimulates the expression of serum- and glucocorticoid-inducible kinase SGK1, a kinase implicated in fibrosing disease [8]. As a matter of fact, SGK1 is required for full stimulation of renal tissue fibrosis following unilateral ureteral obstruction [6]. SGK1-dependent signaling includes phosphorylation and thus inhibition of the glycogen synthase kinase GSK-3 [9-11], which has in turn been implicated in the development of organ hypertrophy, fibrosis and EMT [6, 11-17]. GSK-3 $\beta$ is further phosphorylated by PKB, both of which are phosphorylated after unilateral ureteral obstruction $[6,18,19]$. In the unilateral ureteral obstruction (UUO) model, GSK-3 beta phosphorylation peaked 3 days after the onset of obstructive injury [6]. GSK-3 $\beta$ phosphorylation is an important early mechanism in the EMT of collecting duct cells [20].

Wnt/ ß-catenin activation is a key event in renal fibrosis following UUO, and inhibition of this pathway reduces myofibroblast activation and renal fibrosis [14, 21]. GSK-3 in its active state initiates the degradation of $ß$-catenin, thereby inhibiting its activity $[22,23]$. Both PKB/SGK and Wnt signaling cascades modify GSK-3, yet via distinct mechanisms and with distinct downstream effects $[24,25]$. A crosstalk of PKB with ß-catenin signaling via GSK-3 has been suggested, but is still elusive $[18,26]$. PKB/SGK-dependent phosphorylation of GSK3 can be disrupted by replacement of the serine within the PKB/SGK phosphorylation sites by alanine (GSK-3 $\alpha^{21 \mathrm{~A} / 21 \mathrm{~A}}$, GSK-3 ${ }^{9 \mathrm{~A} / 9 \mathrm{~A}}$ ) [18]. Gene-targeted mice carrying these mutations ( $g s k$ $3^{K I}$ ) should thus be resistant to signaling requiring PKB/SGK-dependent phosphorylation of GSK-3 $\alpha / \beta[18,27]$.

In order to explore whether PKB/SGK-dependent phosphorylation of GSK-3 $\alpha / \beta$ participates in the initiation of renal tissue fibrosis following obstructive nephropathy, the effects of shortterm unilateral ureteral obstruction $[28,29]$ were compared in $g s k-3^{K I}$ mice and corresponding wild-type mice $\left(g s k-3^{W T}\right)$.

\section{Materials and Methods}

\section{Animals}

All animal experiments were conducted according to the German law for the welfare of animals and were approved by local authorities. Experiments have been performed in gene-targeted mice carrying a mutant GSK-3 $\alpha / \beta$, in which the codon encoding Ser9 of the GSK-3ß gene was changed to encode nonphosphorylatable alanine (GSK-3 $\beta^{9 \mathrm{~A} / 9 \mathrm{~A}}$ ), and simultaneously the codon encoding Ser21 of GSK-3 $\alpha$ was changed to encode the nonphosphorylatable GSK-3 $\alpha^{21 \mathrm{~A} / 21 \mathrm{~A}}$ thus yielding the GSK-3 $\alpha / \beta^{21 \mathrm{~A} / 21 \mathrm{~A} / 9 \mathrm{~A} / 9 \mathrm{~A}}$ double knockin mouse $\left(g s k-3^{K I}\right)$ as described previously $[18,27]$. The mice were compared to corresponding wild-type mice $\left(g s k-3^{W T}\right)$.

\section{Unilateral ureteral obstruction}

Renal fibrosis was induced by unilateral ureteral obstruction (UUO) [28, 29]. Following surgical incision of the skin and peritoneum, the left ureter was exposed and ligated twice with a non-resorbable 7-0 filament. Following ligation the surgical wound was closed by sutures. Mice were treated with metamizole 


\section{Kidney \\ Blood Pressure Research}

Kidney Blood Press Res 2013;38:156-164

\begin{tabular}{l|l}
\hline DOI: $10.1159 / 000355763$ & C 2014 S. Karger AG, Basel
\end{tabular}

Published online: March 15, 2014

www.karger.com/kbr

for analgesia $(200 \mathrm{mg} / \mathrm{kg} \mathrm{BW})$ after the procedure and for the duration of the UUO experiment in drinking water. The mice were sacrificed 3 days after the ligation procedure and the obstructed as well as the nonligated kidney rapidly removed and kidney tissues snap frozen in liquid nitrogen.

Quantitative RT-PCR

Total RNA was isolated from murine kidney tissues using Trifast Reagent (Peqlab) according to the manufacturer's instructions. Reverse transcription of $2 \mu \mathrm{g}$ RNA was performed using oligo(dT) ${ }_{12-18}$ primers (Invitrogen) and SuperScript III Reverse Transcriptase (Invitrogen). Quantitative real-time PCR was performed with the iCycler iQ ${ }^{\mathrm{TM}}$ Real-Time PCR Detection System (Bio-Rad Laboratories) and iQ Sybr Green Supermix (Bio-Rad Laboratories) according to the manufacturer's instructions. The following primers were used ( $5^{\prime} \rightarrow 3^{\prime}$ orientation):

$a$-Sma fw: CCCAGACATCAGGGAGTAATGG; $a$-Sma rev: CTATCGGATACTTCAGCGTCA;

$c-M y c$ fw: ATGCCCCTCAACGTGAACTTC; $c$-Myc rev: GTCGCAGATGAAATAGGGCTG;

Col1a1fw:ACCCGAGGTATGCTTGATCTG; Col1a1rev:CATTGCACGTCATCGCACAC;

Col3a1fw:CCATTTGGAGAATGTTGTGCAAT; Col3a1rev:GGACATGATTCACAGATTCCAGG;

$D k k 1$ fw: CAATTCCAACGCGATCAAGAAC; $D k k 1$ rev: CCGCCCTCATAGAGAACTCC;

Gapdh fw: AGGTCGGTGTGAACGGATTTG; Gapdh rev: TGTAGACCATGTAGTTGAGGTCA;

Lef1 fw: TGTTTATCCCATCACGGGTGG; Lef1 rev: CATGGAAGTGTCGCCTGACAG;

Twist fw: GGACAAGCTGAGCAAGATTCA; Twist rev: CGGAGAAGGCGTAGCTGAG.

The specificity of the PCR products was confirmed by analysis of the melting curves. All PCRs were performed in duplicate, and mRNA fold changes were calculated by the $2^{-\Delta \Delta C t}$ method using Gapdh as internal reference. Results are shown normalized to the mRNA expression in the obstructed kidney tissues of $g s k-3^{W T}$ mice.

\section{Western blot analysis}

Murine kidney tissues were lysed with ice-cold lysis buffer (Thermo Fisher Scientific) supplemented with complete protease and phosphatase inhibitor cocktail (Thermo Fisher Scientific). After centrifugation at $10000 \mathrm{rpm}$ for $5 \mathrm{~min}$, proteins were boiled in Roti-Load1 Buffer (Carl Roth $\mathrm{GmbH}$ ) at $100^{\circ} \mathrm{C}$ for $10 \mathrm{~min}$. Proteins were separated on SDS-polyacrylamide gels and transferred to PVDF membranes. The membranes were incubated overnight at $4^{\circ} \mathrm{C}$ with the following primary antibodies: rabbit anti- $\alpha$-smooth muscle actin, rabbit anti-collagen I (used at a 1:1000 dilution, Abcam), rabbit anti-phospho GSK-3 $\alpha / \beta$ (Ser21/9), rabbit anti-GSK-3 $\alpha$, rabbit anti-GSK-3 $\beta$, rabbit anti- $\beta$-catenin, rabbit anti-GAPDH antibody (used at a 1:1000 dilution, Cell Signaling) and then with secondary goat anti-rabbit HRP-conjugated antibody (diluted 1:1000, Cell Signaling) for 1 hour at room temperature. For loading controls, the membranes were stripped with stripping buffer (Carl Roth $\mathrm{GmbH}$ ) at $56^{\circ} \mathrm{C}$ for 5 min. Antibody binding was detected with the ECL detection reagent (Thermo Fisher Scientific). Bands were quantified with Quantity One Software (Bio-Rad Laboratories) and results are shown as the ratio of phosphorylated to total protein and as the ratio of total protein to Gapdh.

\section{Statistics}

Data are provided as means \pm SEM, $n$ represents the number of independent experiments. All data were tested for significance between genotypes using unpaired Student $t$-test (normally distributed data) or Mann-Whitney test (non-normally distributed data) according to Shapiro-Wilk test. Only results with $p<$ 0.05 were considered statistically significant.

\section{Results}

In a first series of experiments, a phospho-specific antibody for GSK-3 $\alpha / \beta$ (Ser21/Ser9) was used to describe the difference in phosphorylation between gsk-3 knockin mice lacking functional PKB/SGK phosphorylation sites of GSK-3 $\alpha / \beta\left(g s k-3^{K I}\right)$ and their corresponding wild-type mice $\left(g s k-3^{W T}\right)$ in the non-obstructed contra-lateral kidney and in the obstructed kidney after a short term obstruction period (3 days). As illustrated in Fig. 1, only weak GSK- 


\section{Kidney Blood Pressure Research}

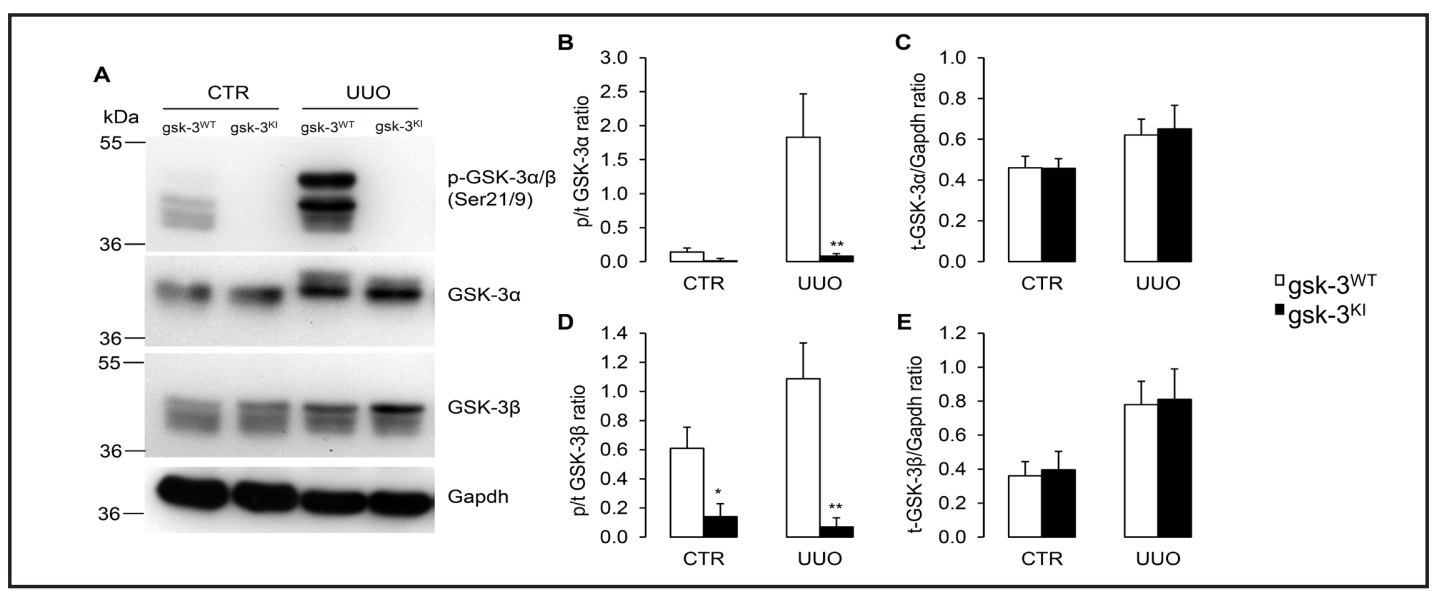

Fig. 1. GSK-3 phosphorylation in renal tissues of gsk- $3^{\mathrm{WT}}$ and gsk- $3^{\mathrm{KI}}$ mice following unilateral ureteral obstruction. A. Representative original western blots showing GSK-3 $\alpha / \beta$ phosphorylation at Ser21/9, total GSK-3 $\alpha$, total GSK-3 $\beta$ and Gapdh protein abundance in kidney tissues of gsk-3 knockin mice lacking functional PKB/ SGK phosphorylation sites in GSK- $3 \alpha / \beta\left(g s k-3^{K I}\right)$ and their corresponding wild-type mice $\left(g s k-3^{W T}\right)$ in non-obstructed control kidneys (CTR) and following unilateral ureteral obstruction (UUO). Arithmetic means \pm SEM $(n=6)$ of phosphorylated/total GSK-3 $\alpha$ (B), total GSK-3 $\alpha$ /Gapdh (C), phosphorylated/total GSK-3 $\beta$ (D) and total GSK-3 $\beta /$ Gapdh (E) protein ratio in kidney tissues of gsk-3 knockin mice lacking functional PKB/SGK phosphorylation sites in GSK-3 $\alpha / \beta$ (gsk-3 ${ }^{K I}$, closed bars) and their corresponding wild-type mice ( $g s k-3^{W T}$, open bars) in non-obstructed control kidneys (CTR) and following unilateral ureteral obstruction (UUO). * (p<0.05), ${ }^{* *}(\mathrm{p}<0.01)$ indicates statistically significant differences from respective kidney tissues of $g s k-3^{W T}$ mice.

$3 \alpha$ and GSK-3 $\beta$ phosphorylation was observed in the non-obstructed kidney tissues of wildtype mice and no phosphorylation of GSK-3 $\alpha$ and GSK-3 3 in renal tissues of $g s k-3^{K I}$ mice. Within three days of unilateral ureteral obstruction, strong GSK-3 $\alpha$ and GSK-3ß phosphorylation was observed in renal tissues from $g s k-3^{W T}$ mice but not from $g s k-3^{K I}$ mice (Fig. 1B,D). In neither, the non-obstructed nor the obstructed kidney tissues, significant differences of total GSK-3 $\alpha$ and GSK-3 $\beta$ protein abundance were observed between the genotypes (Fig. 1C,E).

To quantify the relevance of PKB/SGK-dependent phosphorylation of GSK- $3 \alpha / \beta$ on the fibrotic response after UUO, the expression of renal $\alpha$-smooth muscle actin was determined (Fig. 2). In the non-obstructed kidney tissues, mRNA levels and protein expression of $\alpha$-smooth muscle actin were low and not significantly different between $g s k-3^{K I}$ and $g s k-3^{W T}$ mice. Following UUO treatment, the $\alpha$-smooth muscle actin mRNA and protein levels were significantly less increased in kidney tissues from $g s k-3^{K I}$ mice than in kidney tissues from $g s k-3^{W T}$ mice.

To further elucidate whether PKB/SGK-dependent phosphorylation of GSK-3 $\alpha / \beta$ participates in the signaling of renal tissue fibrosis following UUO, the expression of type I collagen and type III collagen was determined (Fig. 3). In non-obstructed kidney tissues, the protein abundance of collagen type I was not significantly different between $g s k-3^{K I}$ mice and $g s k-3^{W T}$ mice. Following UUO, the protein expression of collagen type I was significantly less increased in kidney tissues from $g s k-3^{K I}$ mice than in kidney tissues from $g s k-3^{W T}$ mice (Fig. 3A,B). Furthermore, in non-obstructed control kidneys the renal mRNA expression of Col1a1 and Col3a1 was low and not significantly different between $g s k-3^{K I}$ mice and $g s k-3^{W T}$ mice. Following obstructive injury, the renal mRNA levels of both, Col1a1 and Col3a1 were again significantly less increased in $g s k-3^{K I}$ mice than in $g s k-3^{W T}$ mice (Fig. 3C,D).

Further experiments addressed the role of PKB/SGK-dependent phosphorylation of GSK$3 \alpha / \beta$ on $\beta$-catenin protein abundance in non-obstructed control kidney tissues or UUO treated kidney tissues from $g s k-3^{K I}$ mice and $g s k-3^{W T}$ mice. As illustrated in Fig. 4, ß-catenin protein expression was not significantly different between non-obstructed kidney tissues from $g s k$ - $3^{K I}$ and $g s k-3^{W T}$ mice. Following UUO treatment, $ß$-catenin protein abundance was significantly less increased in renal tissues from $g s k-3^{K I}$ mice as compared to renal tissues from $g s k-3^{W T}$ mice. 


\section{Kidney \\ Blood Pressure Research}

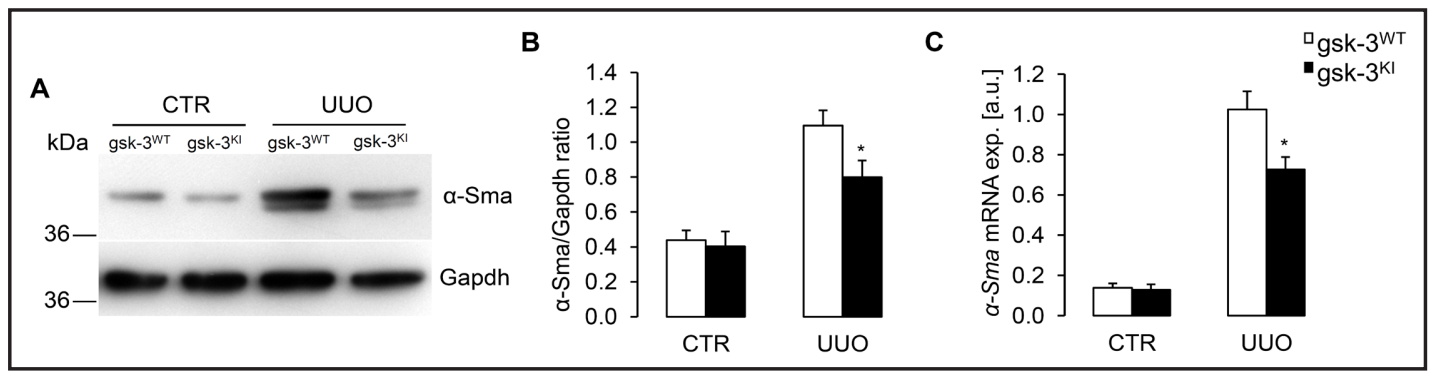

Fig. 2. $\alpha$-Smooth muscle actin expression in renal tissues of gsk- $3^{\mathrm{WT}}$ and gsk- $3^{\mathrm{KI}}$ mice following unilateral ureteral obstruction. A. Representative original western blots showing $\alpha$-smooth muscle actin ( $\alpha$-Sma) and Gapdh protein abundance in kidney tissues of gsk-3 knockin mice lacking functional PKB/SGK phosphorylation sites in GSK-3 $\alpha / \beta\left(g s k-3^{K I}\right)$ and their corresponding wild-type mice $\left(g s k-3^{W T}\right)$ in non-obstructed control kidneys (CTR) and following unilateral ureteral obstruction (UUO). B. Arithmetic means \pm SEM $(n=6)$ of $\alpha$-smooth muscle actin/Gapdh protein ratio in kidney tissues of gsk-3 knockin mice lacking functional PKB/SGK phosphorylation sites in GSK-3 $\alpha / \beta$ (gsk- ${ }^{K I}$, closed bars) and their corresponding wild-type mice ( $g s k$ - $3^{W T}$, open bars) in non-obstructed control kidneys (CTR) and following unilateral ureteral obstruction (UUO). C. Arithmetic means \pm SEM ( $n=7$; arbitrary units) of $\alpha$-smooth muscle actin $(\alpha-S m a)$ relative mRNA expression in kidney tissues of gsk-3 knockin mice lacking functional PKB/SGK phosphorylation sites in GSK-3 $\alpha / \beta$ ( $g s k-3^{K I}$, closed bars) and their corresponding wild-type mice ( $g s k-3^{W T}$, open bars) in non-obstructed control kidneys (CTR) and following unilateral ureteral obstruction (UUO). ${ }^{*}(\mathrm{p}<0.05)$ indicates statistically significant differences from respective kidney tissues of $g s k-3^{W T}$ mice.

Fig. 3. Collagen expression in renal tissues of gsk-3 ${ }^{\text {WT }}$ and gsk-3 ${ }^{\mathrm{KI}}$ mice following unilateral ureteral obstruction. A. Representative original western blots showing collagen type I and Gapdh protein abundance in kidney tissues of gsk-3 knockin mice lacking functional PKB/SGK phosphorylation sites in GSK- $3 \alpha / \beta$ $\left(g s k-3^{K}\right)$ and their corresponding wild-type mice ( $\left.g s k-3^{W T}\right)$ in non-obstructed control kidneys (CTR) and following unilateral ureteral obstruction (UUO). B. Arithmetic means \pm SEM $(n=6)$ of collagen type I/

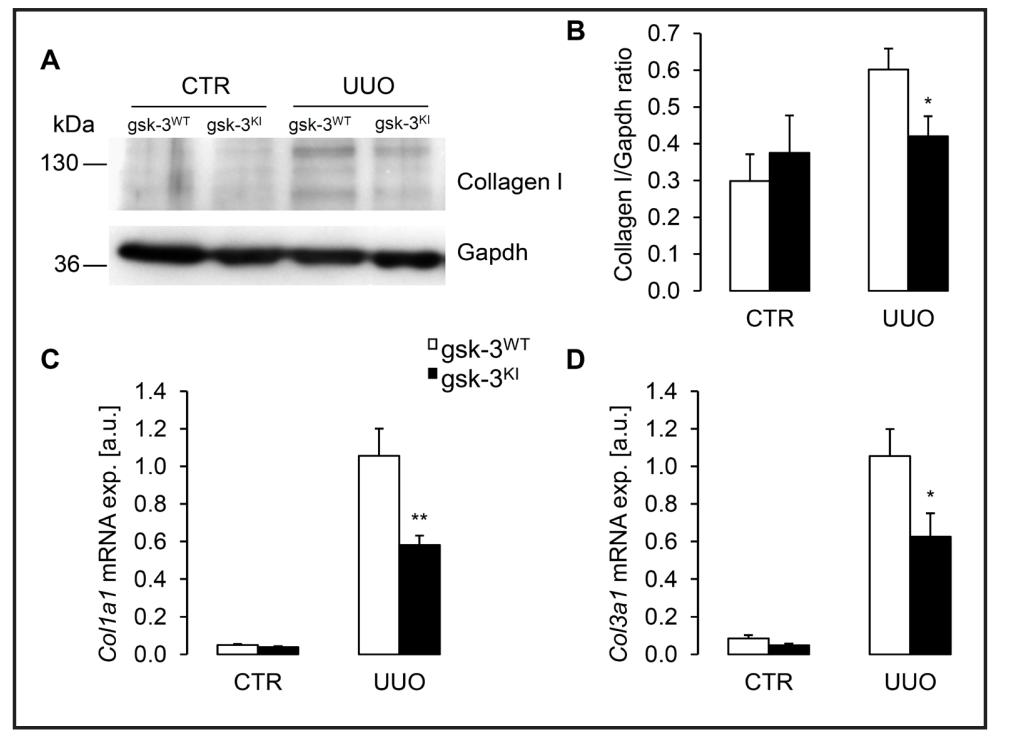

Gapdh protein ratio in kidney tissues of gsk-3 knockin mice lacking functional PKB/SGK phosphorylation sites in GSK-3 $\alpha / \beta$ (gsk- $3^{K I}$, closed bars) and their corresponding wild-type mice ( $g s k-3^{W T}$, open bars) in non-obstructed control kidneys (CTR) and following unilateral ureteral obstruction (UUO). Arithmetic means \pm SEM $(\mathrm{n}=7$; arbitrary units) of collagen type I (Col1a1, C) and collagen type III (Col3a1, D) relative mRNA expression in kidney tissues of gsk-3 knockin mice lacking functional PKB/SGK phosphorylation sites in GSK-3 $\alpha / \beta\left(g s k-3^{K I}\right.$, closed bars) and their corresponding wild-type mice ( $g s k-3^{W T}$, open bars) in non-obstructed control kidneys (CTR) and following unilateral ureteral obstruction (UUO). ${ }^{*}(\mathrm{p}<0.05),{ }^{* *}(\mathrm{p}<0.01)$ indicates statistically significant differences from respective kidney tissues of $g s k-3^{W T}$ mice.

In order to explore the functional significance of differences in ß-catenin protein abundance in $g s k-3^{K I}$ and $g s k-3^{W T}$ mice following obstructive injury, the transcript levels of ß-catenin sensitive genes [14]: $c-M y c$, Dickkopf 1 (Dkk1), Twist and lymphoid enhancer- 


\section{Kidney Blood Pressure Research}

Fig. 4. ß-catenin protein abundance in renal tissues of gsk- $3^{\mathrm{WT}}$ and gsk- $3^{\mathrm{KI}}$ mice following unilateral ureteral obstruction. A. Representative original western blots showing ß-catenin and Gapdh protein abundance in kidney tissues of gsk-3 knockin mice lacking functional

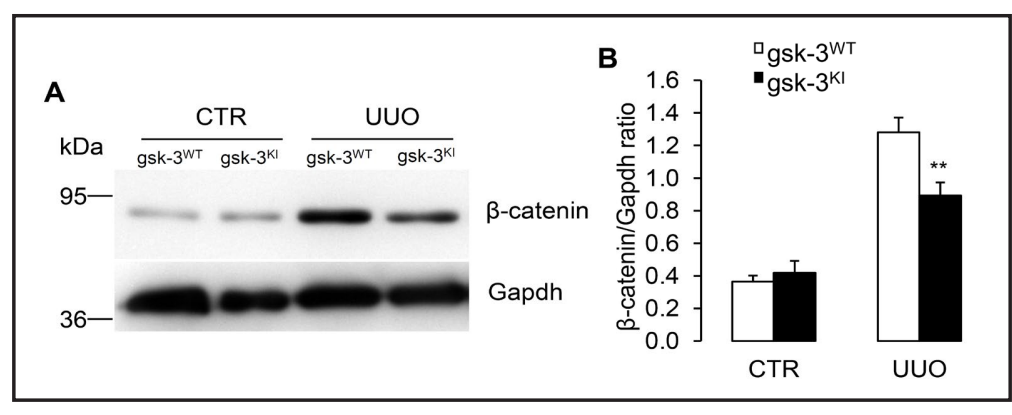

PKB/SGK phosphorylation sites in GSK-3 $\alpha / \beta\left(g s k-3^{K}\right)$ and their corresponding wild-type mice $\left(g s k-3^{W T}\right)$ in non-obstructed control kidneys (CTR) and following unilateral ureteral obstruction (UUO). B. Arithmetic means \pm SEM $(n=6)$ of $\beta$-catenin/Gapdh protein ratio in kidney tissues of gsk-3 knockin mice lacking functional PKB/ SGK phosphorylation sites in GSK- $3 \alpha / \beta$ (gsk- $3^{K I}$, closed bars) and their corresponding wild-type mice (gsk$3^{W T}$, open bars) in non-obstructed control kidneys (CTR) and following unilateral ureteral obstruction (UUO). ${ }^{* *}(\mathrm{p}<0.01)$ indicates statistically significant differences from respective kidney tissues of $g s k-3^{W T}$ mice.

Fig. 5. Expression of $ß$-catenin target genes in renal tissues of gsk- ${ }^{\text {WT }}$ and gsk-3 ${ }^{\mathrm{KI}}$ mice following unilateral ureteral obstruction. Arithmetic means \pm SEM (n=7; arbitrary units) of $c-M y c$ (A), Dickkopf 1 (Dkk1, B), Twist (C) and lymphoid enhancer-binding factor 1 (Lef1, D) relative mRNA expression in kidney tissues of gsk-3 knockin mice lacking functional PKB/ SGK phosphorylation sites in GSK-3 $\alpha / \beta$ (gsk- $3^{K I}$, closed bars) and their corresponding wildtype mice ( $g s k-3^{W T}$, open bars) in non-obstructed control kidneys (CTR) and following unilateral ureteral obstruction (UUO).

\section{A}

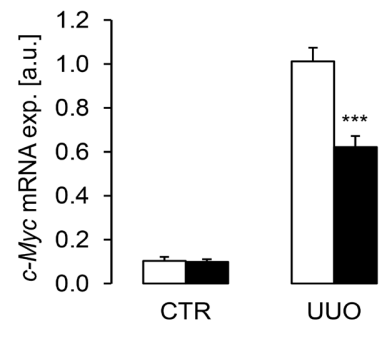

C

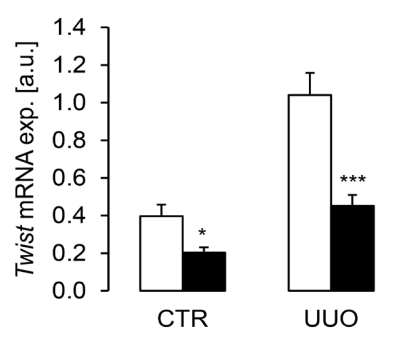

B

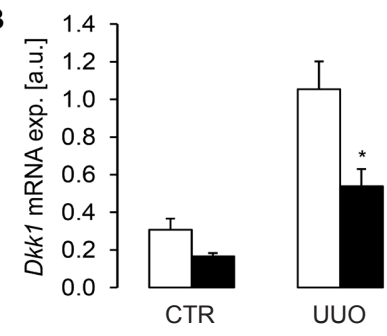

D

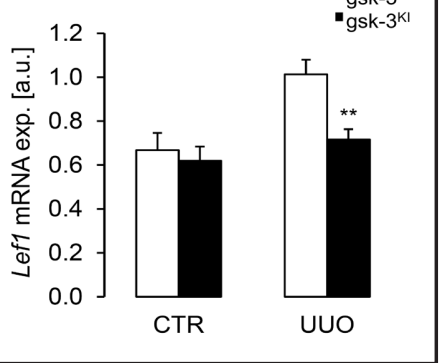
$*(\mathrm{p}<0.05),{ }^{* *}(\mathrm{p}<0.01),{ }^{* * *}(\mathrm{p}<0.001)$ indicate statistically significant differences from respective kidney tissues of $g s k-3^{W T}$ mice.

binding factor 1 (Lef1) were determined. As shown in Fig. 5, in the non-obstructed kidney tissues, the renal expression of the genes encoding: $c-M y c, D k k 1$ and Lef1 were not significantly different between $g s k-3^{K I}$ and $g s k-3^{W T}$ mice. The mRNA expression of Twist was significantly lower in the non-obstructed kidney tissues of $g s k-3^{K I}$ mice as compared to non-obstructed kidney tissues from gsk-3 ${ }^{W T}$ mice. Following UUO treatment, the renal transcript levels of the ß-catenin target genes: $c-M y c, D k k 1$, Twist and Lef1 were significantly less increased in renal tissues from $g s k-3^{K I}$ mice than in renal tissues from $g s k-3^{W T}$ mice.

\section{Discussion}

The present study sheds new light on the signaling of renal fibrosis following obstructive nephropathy. Disruption of PKB and SGK1-dependent phosphorylation of glycogen synthase 


\section{Kidney Blood Pressure Research}

Kidney Blood Press Res 2013;38:156-164

\begin{tabular}{l|l}
\hline DOI: 10.1159/000355763 & (c) 2014 S. Karger AG, Basel \\
www.karger.com/kbr
\end{tabular}

Published online: March 15, 2014

Voelkl/Mia/Meissner/Ahmed/Feger/Elvira/Walker/Alessi/Alesutan/Lang: PKB/SGKResistant GSK-3 in UUO

kinase GSK- $3 \alpha / \beta$ significantly blunted the increase of collagen and $\alpha$-smooth muscle actin expression following short term UUO. Furthermore, the renal $\beta$-catenin protein abundance and transcript levels of the ß-catenin target genes: $c-M y c, D k k 1$, Twist and Lef1 following obstructive injury were significantly less increased in $g s k-3^{K I}$ mice than in $g s k-3^{W T}$ mice.

Previous studies revealed the critical involvement of TGFß in the triggering of fibrosis of the kidney [2]. GSK-3 inactivation is an important mechanism in TGFß-induced senescence [30]. TGFß stimulates the expression of SGK1 [8], which in turn significantly contributes to the stimulation of renal fibrosis following unilateral ureteral obstruction [6]. SGK1 is presumably at least in part effective by phosphorylating glycogen synthase kinase GSK-3, a known target of both SGK and AKT isoforms [9-11]. Both, AKT and SGK1 are upregulated following renal obstruction leading to increased phosphorylation of GSK-3 $\beta[6,19]$. Ample evidence points to a significant role of GSK-3 in the regulation of fibroblast differentiation and tissue fibrosis $[6,11,12,14,15]$. In cardiac tissue, for instance, the remodelling and fibrosis following beta-adrenergic challenge was blunted in $g s k-3^{K l}$ mice [31].

A key signaling pathway promoting renal fibrosis is the Wnt/ß-catenin pathway [14, 21]. Wnt signals through GSK-3 to stabilize $B$-catenin, a signaling process distinct from PKB/SGK1 signaling $[22,23,32]$. The $ß$-catenin protein abundance is similarly low in non-obstructed kidneys of $g s k-3^{K I}$ and $g s k-3^{W T}$ mice, but the increase of $ß$-catenin protein abundance in obstructed kidneys was blunted in $g s k-3^{K I}$ mice as compared to $g s k-3^{W T}$ mice. Following UUO, inhibition of PKB/SGK1-dependent phosphorylation of GSK-3 thus impacts on the Wnt/ß-catenin signaling pathway. Akt-sensitive ß-catenin activity has been observed earlier [32, 33]. The effect of PKB/SGK1 signaling on ß-catenin is, however, not necessarily direct, but could be secondary to other mechanisms [32]. For example, PKB/SGK1 - GSK-3 signaling regulates Snail, which fosters activation of $ß$-catenin and could thereby serve as the link between PI3K and Wnt/ß-catenin signalling $[6,16,17,20,34]$. In accordance with previous observations, PKB/SGK1-dependent GSK- $3 \alpha / \beta$ phosphorylation is nonetheless an important event in renal fibrosis signaling $[6,20]$.

$\mathrm{PKB} / \mathrm{SGK}$ is an important target for TGF $\beta$ in renal disease [8, 35]. At least in theory, PKB/ SGK-dependent phosphorylation of GSK- $3 \alpha / \beta$ could similarly participate in the mechanisms triggering renal tissue fibrosis following other challenges, such as diabetes, hypertension and renal ischemia $[1,17,20]$. It is noteworthy that SGK1 is highly expressed in diabetic nephropathy [36] and kidney biopsies from proteinuric renal failure patients [37]. Moreover, SGK1 appears to be critically important for renal [38] and cardiac [15, 39, 40] fibrosis. Notably, mineralocorticoid-induced cardiac fibrosis was paralleled by enhanced GSK-3 phosphorylation, which was, however, not dependent on SGK1 and may have at least in part been due to phosphorylation by PKB isoforms [11].

\section{Conclusion}

AKT and SGK1-dependent phosphorylation of glycogen synthase kinase GSK-3 $\alpha / \beta$ participates in the signaling leading to renal tissue fibrosis and its disruption blunts the stimulation of fibrosis markers following unilateral ureteral obstruction.

\section{Conflict of Interests}

All authors disclose that they have no potential conflict of interest.

\section{Acknowledgements}

This study was supported by the Deutsche Forschungsgemeinschaft and the Open Access Publishing Fund of Tuebingen University. The authors acknowledge the technical 


\section{Kidney \\ Blood Pressure Research}

Kidney Blood Press Res 2013;38:156-164

\begin{tabular}{l|l}
\hline DOI: $10.1159 / 000355763$ & (C) 2014 S. Karger AG, Basel
\end{tabular}

Published online: March 15, 2014

www.karger.com/kbr

Resistant GSK-3 in UUO

assistance of E. Faber and the meticulous preparation of the manuscript by A. Soleimanpour and T. Loch.

\section{References}

1 Bascands JL, Schanstra JP: Obstructive nephropathy: insights from genetically engineered animals. Kidney Int 2005;68:925-937.

2 Samarakoon R, Overstreet JM, Higgins SP, Higgins PJ: TGF-beta1 --> SMAD/p53/USF2 --> PAI-1 transcriptional axis in ureteral obstruction-induced renal fibrosis. Cell Tissue Res 2012;347:117-128.

3 Grgic I, Duffield JS, Humphreys BD: The origin of interstitial myofibroblasts in chronic kidney disease. Pediatr Nephrol 2012;27:183-193.

$4 \quad$ Kriz W, Kaissling B, Le Hir M: Epithelial-mesenchymal transition (EMT) in kidney fibrosis: fact or fantasy? J Clin Invest 2011;121:468-474.

5 Liu Y: New insights into epithelial-mesenchymal transition in kidney fibrosis. J Am Soc Nephrol 2010;21:212-222.

6 Cheng J, Truong LD, Wu X, Kuhl D, Lang F, Du J: Serum- and glucocorticoid-regulated kinase 1 is upregulated following unilateral ureteral obstruction causing epithelial-mesenchymal transition. Kidney Int 2010;78:668-678.

7 Yanagita M: Inhibitors/antagonists of TGF-beta system in kidney fibrosis. Nephrol Dial Transplant 2012;27:3686-3691.

8 Lang F, Bohmer C, Palmada M, Seebohm G, Strutz-Seebohm N, Vallon V: (Patho)physiological significance of the serum- and glucocorticoid-inducible kinase isoforms. Physiol Rev 2006;86:1151-1178.

9 Sakoda H, Gotoh Y, Katagiri H, Kurokawa M, Ono H, Onishi Y, Anai M, Ogihara T, Fujishiro M, Fukushima Y, Abe M, Shojima N, Kikuchi M, Oka Y, Hirai H, Asano T: Differing roles of Akt and serum- and glucocorticoid-regulated kinase in glucose metabolism, DNA synthesis, and oncogenic activity. J Biol Chem 2003;278:25802-25807.

10 Shaw M, Cohen P, Alessi DR: Further evidence that the inhibition of glycogen synthase kinase-3beta by IGF1 is mediated by PDK1/PKB-induced phosphorylation of Ser-9 and not by dephosphorylation of Tyr-216. FEBS Lett 1997;416:307-311.

11 Wyatt AW, Hussain A, Amann K, Klingel K, Kandolf R, Artunc F, Grahammer F, Huang DY, Vallon V, Kuhl D, Lang F: DOCA-induced phosphorylation of glycogen synthase kinase 3beta. Cell Physiol Biochem 2006;17:137-144.

12 Aoyama T, Matsui T, Novikov M, Park J, Hemmings B, Rosenzweig A: Serum and glucocorticoid-responsive kinase-1 regulates cardiomyocyte survival and hypertrophic response. Circulation 2005;111:1652-1659.

13 Hardt SE, Sadoshima J: Glycogen synthase kinase-3beta: a novel regulator of cardiac hypertrophy and development. Circ Res 2002;90:1055-1063.

14 He W, Dai C, Li Y, Zeng G, Monga SP, Liu Y: Wnt/beta-catenin signaling promotes renal interstitial fibrosis. J Am Soc Nephrol 2009;20:765-776.

15 Vallon V, Wyatt AW, Klingel K, Huang DY, Hussain A, Berchtold S, Friedrich B, Grahammer F, Belaiba RS, Gorlach A, Wulff P, Daut J, Dalton ND, Ross J, Jr., Flogel U, Schrader J, Osswald H, Kandolf R, Kuhl D, Lang F: SGK1-dependent cardiac CTGF formation and fibrosis following DOCA treatment. J Mol Med (Berl) 2006;84:396-404.

16 Zheng H, Li W, Wang Y, Liu Z, Cai Y, Xie T, Shi M, Wang Z, Jiang B: Glycogen synthase kinase-3 beta regulates Snail and beta-catenin expression during Fas-induced epithelial-mesenchymal transition in gastrointestinal cancer. Eur J Cancer 2013;49:2734-2746.

17 Doble BW, Woodgett JR: Role of glycogen synthase kinase-3 in cell fate and epithelial-mesenchymal transitions. Cells Tissues Organs 2007;185:73-84.

18 McManus EJ, Sakamoto K, Armit LJ, Ronaldson L, Shpiro N, Marquez R, Alessi DR: Role that phosphorylation of GSK3 plays in insulin and Wnt signalling defined by knockin analysis. EMBO J 2005;24:1571-1583.

19 Rodriguez-Pena AB, Grande MT, Eleno N, Arevalo M, Guerrero C, Santos E, Lopez-Novoa JM: Activation of Erk1/2 and Akt following unilateral ureteral obstruction. Kidney Int 2008;74:196-209.

20 Ivanova L, Butt MJ, Matsell DG: Mesenchymal transition in kidney collecting duct epithelial cells. Am J Physiol Renal Physiol 2008;294:F1238-1248. 


\section{Kidney \\ Blood Pressure Research}

Kidney Blood Press Res 2013;38:156-164

\begin{tabular}{l|l}
\hline DOI: $10.1159 / 000355763$ & (c) 2014 S. Karger AG, Basel
\end{tabular}

Published online: March 15, 2014

www.karger.com/kbr

Resistant GSK-3 in UUO

21 Zhou L, Li Y, Zhou D, Tan RJ, Liu Y: Loss of Klotho contributes to kidney injury by derepression of Wnt/betacatenin signaling. J Am Soc Nephrol 2013;24:771-785.

22 Wu D, Pan W: GSK3: a multifaceted kinase in Wnt signaling. Trends Biochem Sci 2010;35:161-168.

$23 \mathrm{Xu}$ C, Kim NG, Gumbiner BM: Regulation of protein stability by GSK3 mediated phosphorylation. Cell Cycle 2009;8:4032-4039.

24 Ding VW, Chen RH, McCormick F: Differential regulation of glycogen synthase kinase 3beta by insulin and Wnt signaling. J Biol Chem 2000;275:32475-32481.

25 Metcalfe C, Bienz M: Inhibition of GSK3 by Wnt signalling--two contrasting models. J Cell Sci 2011;124:3537-3544.

26 Ng SS, Mahmoudi T, Danenberg E, Bejaoui I, de Lau W, Korswagen HC, Schutte M, Clevers H: Phosphatidylinositol 3-kinase signaling does not activate the wnt cascade. J Biol Chem 2009;284:3530835313.

27 Bouskila M, Hunter RW, Ibrahim AF, Delattre L, Peggie M, van Diepen JA, Voshol PJ, Jensen J, Sakamoto K: Allosteric regulation of glycogen synthase controls glycogen synthesis in muscle. Cell Metab 2010;12:456466.

28 Chevalier RL, Forbes MS, Thornhill BA: Ureteral obstruction as a model of renal interstitial fibrosis and obstructive nephropathy. Kidney Int 2009;75:1145-1152.

29 Xiong M, Gong J, Liu Y, Xiang R, Tan X: Loss of vitamin D receptor in chronic kidney disease: a potential mechanism linking inflammation to epithelial-to-mesenchymal transition. Am J Physiol Renal Physiol 2012;303:F1107-F1115.

30 Byun HO, Jung HJ, Seo YH, Lee YK, Hwang SC, Hwang ES, Yoon G: GSK3 inactivation is involved in mitochondrial complex IV defect in transforming growth factor (TGF) beta1-induced senescence. Exp Cell Res 2012;318:1808-1819.

31 Webb IG, Nishino Y, Clark JE, Murdoch C, Walker SJ, Makowski MR, Botnar RM, Redwood SR, Shah AM, Marber MS: Constitutive glycogen synthase kinase-3alpha/beta activity protects against chronic betaadrenergic remodelling of the heart. Cardiovasc Res 2010;87:494-503.

32 Voskas D, Ling LS, Woodgett JR: Does GSK-3 provide a shortcut for PI3K activation of Wht signalling? F1000 Biol Rep 2010;2:82.

33 Monick MM, Carter AB, Robeff PK, Flaherty DM, Peterson MW, Hunninghake GW: Lipopolysaccharide activates Akt in human alveolar macrophages resulting in nuclear accumulation and transcriptional activity of beta-catenin. J Immunol 2001;166:4713-4720.

34 Lee YJ, Han HJ: Troglitazone ameliorates high glucose-induced EMT and dysfunction of SGLTs through PI3K/Akt, GSK-3beta, Snail1, and beta-catenin in renal proximal tubule cells. Am J Physiol Renal Physiol 2010;298:F1263-1275.

35 Kato M, Putta S, Wang M, Yuan H, Lanting L, Nair I, Gunn A, Nakagawa Y, Shimano H, Todorov I, Rossi JJ, Natarajan R: TGF-beta activates Akt kinase through a microRNA-dependent amplifying circuit targeting PTEN. Nat Cell Biol 2009;11:881-889.

36 Lang F, Klingel K, Wagner CA, Stegen C, Warntges S, Friedrich B, Lanzendorfer M, Melzig J, Moschen I, Steuer S, Waldegger S, Sauter M, Paulmichl M, Gerke V, Risler T, Gamba G, Capasso G, Kandolf R, Hebert SC, Massry SG, Broer S: Deranged transcriptional regulation of cell-volume-sensitive kinase hSGK in diabetic nephropathy. Proc Natl Acad Sci USA 2000;97:8157-8162.

37 Quinkler M, Zehnder D, Eardley KS, Lepenies J, Howie AJ, Hughes SV, Cockwell P, Hewison M, Stewart PM: Increased expression of mineralocorticoid effector mechanisms in kidney biopsies of patients with heavy proteinuria. Circulation 2005;112:1435-1443.

38 Artunc F, Amann K, Nasir O, Friedrich B, Sandulache D, Jahovic N, Risler T, Vallon V, Wulff P, Kuhl D, Lang F: Blunted DOCA/high salt induced albuminuria and renal tubulointerstitial damage in gene-targeted mice lacking SGK1. J Mol Med (Berl) 2006;84:737-746.

39 Voelkl J, Lin Y, Alesutan I, Ahmed MS, Pasham V, Mia S, Gu S, Feger M, Saxena A, Metzler B, Kuhl D, Pichler BJ, Lang F: Sgk1 sensitivity of $\mathrm{Na}(+) / \mathrm{H}(+)$ exchanger activity and cardiac remodeling following pressure overload. Basic Res Cardiol 2012;107:236.

40 Voelkl J, Pasham V, Ahmed MS, Walker B, Szteyn K, Kuhl D, Metzler B, Alesutan I, Lang F: Sgk1-dependent stimulation of cardiac na/h(+) exchanger nhe1 by dexamethasone. Cell Physiol Biochem 2013;32:25-38. 